\title{
A Review of Prevalence and Pattern of Intestinal Parasites in Nigeria (2006-2015)
}

\author{
Oluwatobiloba Ibukunoluwa Funso-Aina, Henry Nnaemeka Chineke, Prosper Obunikem Adogu
}

\begin{abstract}
Intestinal worm infestation has become a global health problem and still highly prevalent in the tropical region. Soil-transmitted helminth (STH) infections form the most important group of intestinal worms affecting two billion people worldwide, causing considerable morbidity and suffering, though largely preventable.

Spatial distribution of helminth infections across the six geopolitical zones of Nigeria identified the following helminthes; Ascaris lumbricoides, hookworm, Trichuris trichiura, S. stercoralis, Taenia sp, S. mansoni, S. stercoralis, Enterobius vermicularis and Hymenolopis nana. This study revealed that prevalence of intestinal helminth in the country has not declined since the 1970s. Ascaris lumbricoides was the most prevalent helminth in the Southwestern $(21 \%)$ and South-southern $(13 \%)$ parts of Nigeria. Hookworm was the most prevalent helminth infection in the Southeastern $(19 \%)$ while multiple infections were highly prevalent in Northern Nigeria $(25 \%$ in Northcentral and $19 \%$ in the Northeast and Northwest, respectively). Cases of Taenia sp and Schistosoma mansoni infections were high in the Northeast and Northwest of Nigeria $(8 \%$ and $6 \%$, respectively).
\end{abstract}

Nigeria has benefited from the Water, Sanitation and Hygiene (WASH) programme for over thirty years in the aspects of enhanced capacity building for applying personal hygiene and sanitation, improved water sources and provision of sanitation facilities and the National Emergency Group for coordination of emergency preparedness and response for WASH-related diseases. WHO estimated that more than $9 \%$ of the disease burden and $6 \%$ of deaths could be prevented by improving the WASH intervention programme. Children suffer the most, as $25 \%$ of global mortality of children (1 month-14 years) was linked with unsafe water and inadequate sanitation or insufficient hygiene, which was polarized in developing countries. To overcome challenge of WASH-related diseases, improved hygiene practices are essential. It is therefore important to sensitize people on the importance of water and sanitation practices through hygiene education. For effectiveness, hygiene education should be incorporated into the curriculum of schools from primary to tertiary institutions. Index Terms-Prevalence; Pattern; Intestinal parasites; Nigeria

\section{INTRODUCTION}

An intestinal parasite infection is a condition in which a parasite infects the gastro-intestinal tract of humans and other animals. Such parasites can live anywhere in the body, but most of them prefer the intestinal wall. Routes of transmission include ingestion of undercooked meat, drinking infected water, fecal-oral transmission and skin absorption. Some types of helminths and protozoa are classified as intestinal parasites that cause infection; those that reside in the intestines. These infections come with

Published on January 16, 2020.

Funso-Aina Oluwatobiloba Ibukunoluwa, Nnamdi Azikiwe University, Awka, Nnewi campus, Nigeria.

(e-mail: ucheadogu@gmail.com) considerable morbidity among humans.

Parasitic infections, caused by intestinal helminths and protozoan parasites, are among the most prevalent infections in humans in developing countries. In developed countries, protozoan parasites more commonly cause gastrointestinal infections compared to helminths. Intestinal parasites cause a significant morbidity and mortality in endemic countries [1]. Helminths are worms with many cells. Nematodes (roundworms), cestodes (tapeworms) and trematodes (flatworms) are among the most common helminths that inhabit the human gut. Usually, helminths cannot multiply in the human body but protozoan parasites that have only one cell can multiply inside the human body. There are four species of intestinal helminthic parasites, also known as geohelminths and soil-transmitted helminths: Ascaris lumbricoides (roundworm), Trichiuris trichiuria (whipworm), Ancylostoma duodenale and Necator americanicus (hookworms). These infections are most prevalent in tropical and subtropical regions of the developing world where adequate water and sanitation facilities are lacking [2], [3].

Intestinal worm infestations are widely prevalent in tropical and subtropical countries and occur where there is poverty and poor sanitation. Soil-transmitted helminth $(\mathrm{STH})$ infections form the most important group of intestinal worms affecting two billion people worldwide and the main species which infect are Ascaris lumbricoides (roundworms), Trichuris trichiura (whipworms) and Necator americanus/Ancylostoma duodenale (hookworms) [4], [5]. According to World Health Organization (WHO), globally there are 1221-1472 million cases of Ascariasis, 750-1050 million cases of Trichuriasis and 740-1300 million cases of hookworm infestation [6]. These STHs are also considered Neglected Tropical Diseases (NTDs) as they inflict considerable morbidity and mortality, though largely preventable [6].

Intestinal helminths rarely cause death. Instead, the burden of disease is related to less mortality than to the chronic and insidious effects on health and nutritional status of the host [7], [8]. In addition to their health effects, intestinal helminth infections also impair physical and mental growth of children, thwart educational achievement, and hinder economic development [9], [10]. The diseases caused by these intestinal protozoan parasites are known as giardiasis (Giardia intestinalis), amoebiasis (Entamoeba histolytica),

Henry Nnaemeka Chineke, Imo State University, Orlu, Nigeria.

(e-mail:prosuperhealth50@gmail.com)

Prosper Obunikem Adogu, Nnamdi Azikiwe University, Awka, Nnewi campus, Nigeria.(e-mail: bright.ifechukwu@gmail.com) 
cyclosporiasis (Cyclospora cayetanenensis) and cryptosporidiosis (Cryptosporidium spp) respectively, and they are associated with diarrhoea [11]. G. intestinalis is the most prevalent parasitic cause of diarrhea in the developed world, and this infection is also very common in developing countries. Amoebiasis is the third leading cause of death from parasitic diseases worldwide, with its greatest impact on the people of developing countries. The World Health Organization (WHO) estimates that approximately 50 million people worldwide suffer from invasive amoebic infection each year, resulting in 40-100 thousand deaths annually [12], [13]. Cryptosporidiosis is becoming most prevalent in both developed and developing countries among patients with AIDS and among children aged less than five years. Several outbreaks of diarrhoeal disease caused by C. cayetanensis have been reported during the last decade [14]. Spread of these protozoan parasites in developing countries mostly occurs through faecal contamination as a result of poor sewage and poor quality of water. Food and water-borne outbreaks of these protozoan parasites have occurred, and the infectious cyst form of the parasites is relatively resistant to chlorine [15]. Other species of protozoan parasites can also be found in the human gut, but they are not pathogenic, except Microsporidia sp.

In Nigeria, intestinal helminth infestations have continued to prevail due of poor standards of living, poor environmental sanitation and ignorance of simple health promoting behaviours [16], [17]. Intestinal helminth infections are most common in school age children and they tend to occur in high intensity in this age group [18]. These infections have been associated with an increased risk for nutritional anaemia, protein-energy malnutrition and growth deficits in children [19]. Several environmental and socio-economic factors have been identified to be responsible for the continued persistence of intestinal parasite infections in children. Some of these are poor sanitary conditions, unhygienic practices, absence of potable water, poor housing facilities and poverty [20]- [23]

The prevalence of intestinal worms in Nigeria has remained high and endemic. As a developing nation, helminthiasis is a public health concern and is classified as a neglected tropical disease which requires close attention due to the fact that the worst hit are children and adults inclusive. Interestingly, pre-disposing factors to intestinal worms are directly and indirectly related to matters of sustainable hygiene and consistent environmental sanitation. A recent World Health Organization report grouped Nigeria as highly infected and clearly above 50\% [5]. This is of serious public health concern knowing that many developed countries have long effectively eliminated the scourge.

This study will provide statistical overview with respect to prevalence rate across the six geopolitical zones of Nigeria and also highlight the impact on the populace. Thus, the researchers are motivated to generate workable recommendations that will possibly mitigate the spread of intestinal worms in the country.

The objectives of this study include to determine the prevalence and trend of intestinal helminthiasis in Nigeria within the period under review; to identify the pattern of helminths responsible for intestinal infestation; and to investigate the various preventive and treatment modalities adopted against the disease over time. to mitigate the disease burden of intestinal worms.

\section{METHODOLOGY}

A. Data sources: All data used in this review covered publications obtained from prevalence studies, personal communications, recent international conference proceedings, World Health Organization reports, World Health Organization/United Nations Children Education Fund joint monitoring programme report and training manual on diagnosis of intestinal parasites. Other sources are journals of Google scholar, Medicine and medical research, Tropical medicine, Medicine and clinical sciences, Helminthology, Acta scientific microbiology, Animal research international, Asian pacific journal of tropical medicine and related repositories.

B. Selection of study samples: Study population for intestinal worms cuts across all ages and involves both genders. Samples from women at different reproductive stages; pre-menstrual, menstrual and post-menstrual can be examined [24]. Volunteers from age five (5) and above with focus on school age children and food vendors [25]. Necessary approval was obtained from school authorities and parents and individual consent was obtained from adults.

C. Questionnaires to collect information on; personal data (sex, age, family size, occupation, level of education, residential area and type of accommodation), household data (source of water, type of toilet, toilet usage and mode of feeding), hygiene data (washing hands before eating, washing hands after defecation and clean up material), knowledge, attitudes and practices regarding intestinal parasitic infections are also administered [25].

\section{RESULT, FIGURES AND TABLES}

Table 1: Prevalence of helminths within the six geopolitical zones of Nigeria

\begin{tabular}{|l|l|l|l|l|l|l|}
\hline $\begin{array}{l}\text { Intestinal } \\
\text { Helminths }\end{array}$ & $\begin{array}{l}\text { South } \\
\text { West } \\
(\%)\end{array}$ & $\begin{array}{l}\text { South } \\
\text { South } \\
(\%)\end{array}$ & $\begin{array}{l}\text { South } \\
\text { East } \\
(\%)\end{array}$ & $\begin{array}{l}\text { North } \\
\text { Central } \\
(\%)\end{array}$ & $\begin{array}{l}\text { North } \\
\text { East } \\
(\%)\end{array}$ & $\begin{array}{l}\text { North } \\
\text { West } \\
(\%)\end{array}$ \\
\hline $\begin{array}{l}\text { Ascaris } \\
\text { Lumbricoides }\end{array}$ & 21 & 13 & 17 & 11 & 15 & 15 \\
\hline Hook worm sp. & 4 & 8 & 19 & 12 & 7 & 7 \\
\hline $\begin{array}{l}\text { Trichuris } \\
\text { Trichiura }\end{array}$ & 7 & 4 & 12 & 4 & 3.5 & 3.5 \\
\hline Taenia sp. & 2 & 1 & 7 & 3 & 7 & 7 \\
\hline $\begin{array}{l}\text { Mixed } \\
\text { infections }\end{array}$ & 2 & 2.5 & 4.5 & 25 & 19 & 19 \\
\hline
\end{tabular}




\section{5}

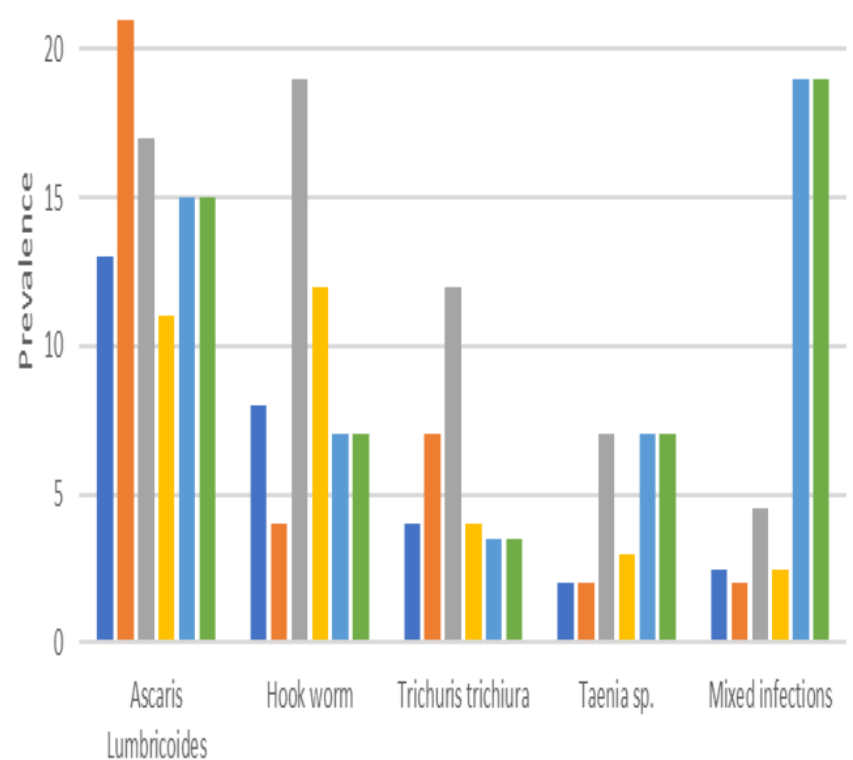

Types of helminths

\section{ISS ISW ISE INC INE INW}

Figure 1: Prevalence of helminthiasis within the six geopolitical zones of Nigeria

Key: SS-South-south, SW- Southwest, SE-South-east, NC-North-central, NE-North-east and NW-North-west.

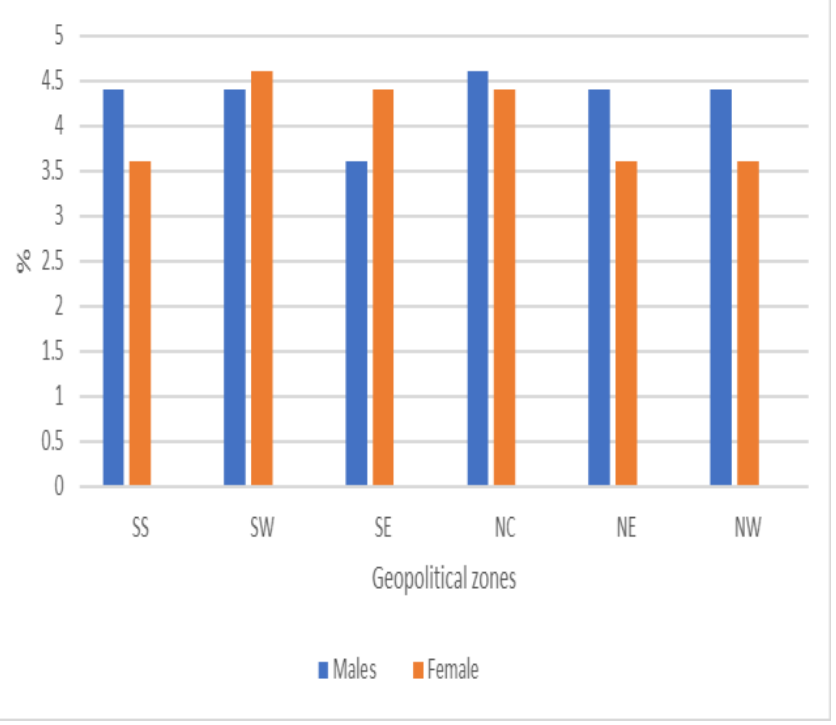

Figure 2: Prevalence of helminths by sexes in the six geopolitical zones of Nigeria

Figure 2 shows prevalence of helminths in Nigeria according to sex in the six geopolitical zones of Nigeria
Table 2: Prevalence of helminths by age group in the six geopolitical zones of Nigeria

\begin{tabular}{|c|c|c|c|c|}
\hline & $0-4$ years & $5-12$ years & $13-19$ years & 20 years and above \\
\hline South-west & $0.7 \%$ & $31.8 \%$ & $56.4 \%$ & $11.3 \%$ \\
\hline South-south & $3.9 \%$ & $15.2 \%$ & $31.8 \%$ & $49.2 \%$ \\
\hline South-east & $4 \%$ & $16.5 \%$ & $28.6 \%$ & $51.1 \%$ \\
\hline North-central & $2.5 \%$ & $15.4 \%$ & $40 \%$ & $42.1 \%$ \\
\hline North-east & $5.6 \%$ & $56.7 \%$ & $35.1 \%$ & $2.7 \%$ \\
\hline North-west & $8.8 \%$ & $58.3 \%$ & $17.2 \%$ & $15.8 \%$ \\
\hline
\end{tabular}

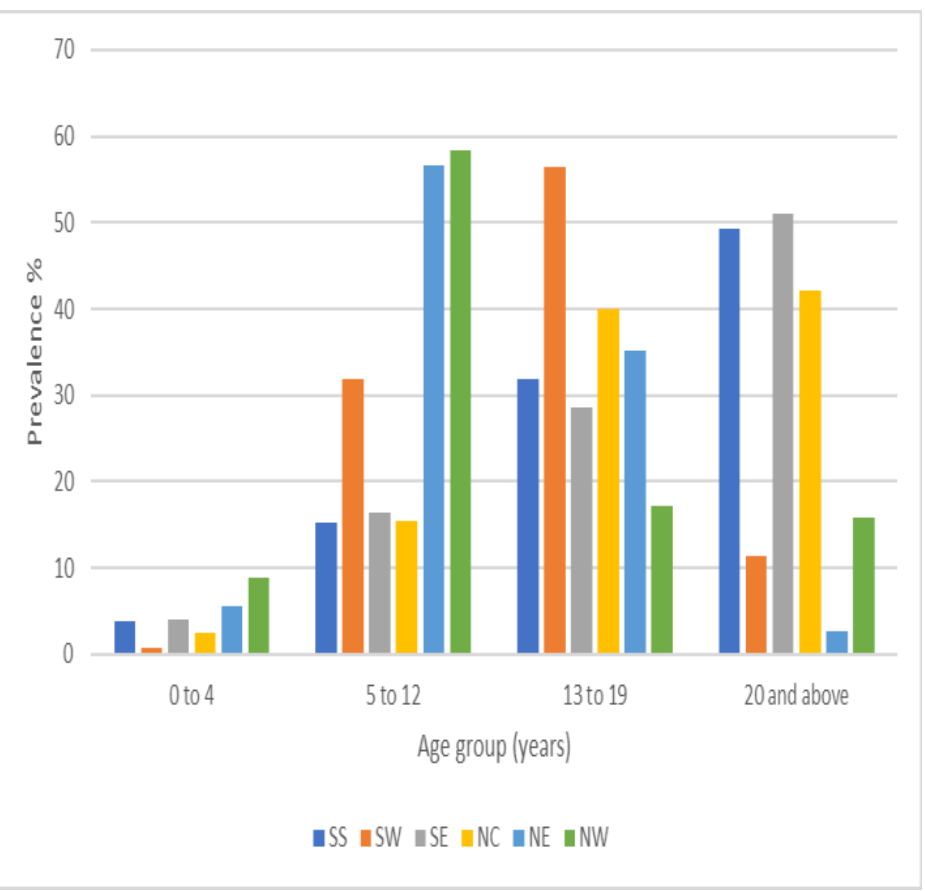

Figure 3: Prevalence of helminths by age groups in the six geopolitical zones of Nigeria

Figure 3 presents data on prevalence of helminths among age groups in the six geopolitical zones of Nigeria. Children aged $0-3$ years were the most infected $(5.6 \%$ and $8.8 \%)$ in North East and North West zones likewise $56.4 \%$ and $40 \%$ respectively are the peak for children aged 13-19 years in the South West and North Central. 


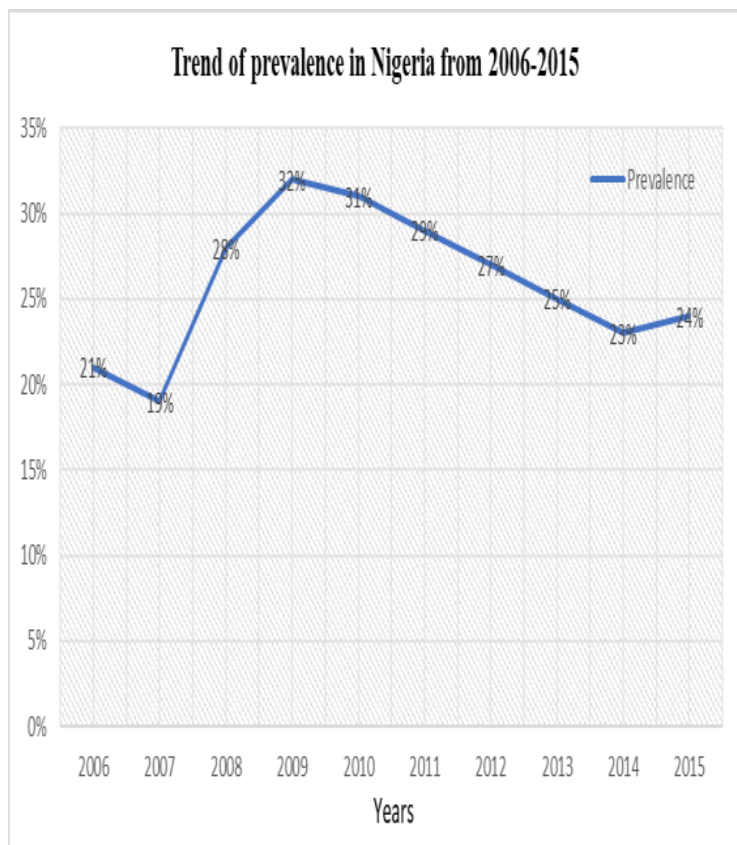

Figure 4: Trend of prevalence in Nigeria from 2006-2015

Figure 4 shows the composite prevalence of helminthiases (Ascaris lumbricoides, Hookworm, Trichuris trichiura, Taenia specie and mixed infections) in the six geopolitical zones of Nigeria.

\section{DISCUSSION}

Intestinal parasitic infections are diseases caused by pathogenic helminths and protozoa species and are among the most common infectious diseases reportedly affecting over 1.5 billion people mostly from the poorest and most deprived communities worldwide.

A close observation of figure 4 shows that the prevalence of helminthiasis in Nigeria within the decade under review has varies from one geopolitical zone to the other. However, the Northern zones have clearly the worst spread and highest average prevalence for all helminthiases. South West and South East zones have the highest prevalence of Ascaris lumbricoides which correlates with the research done independently by Arosoye, Damen and Gimba [25]- [27]. This can be attributed to ownership of domestic animals and food ingestion without due attention to proper hand washing practice especially after defecating. Hookworm infection is highest in both the South East and North Central zones followed closely by Trichuris trichiura. Taenia specie is least in all zones which can perhaps be attributed to slightly improved meat cooking culture.

Mixed infections are at peak in all Northern zones over the decade-long study. This gives serious cause for concern because the impact of recommendations as itemized by Damen and Kpurkpur [26], [28] appear to have been checkmated. In the FCT, Gimba [27] identified Ascaris lumbricoides and Entamoeba histolytica with $42.9 \%$ and $38.1 \%$ prevalence respectively, as the leading parasites responsible for diarrheal diseases in children aged under 5years in Gwagwalada Area Council.
Data from the reviewed literatures show a close margin and insignificant difference between sexes in South West and North Central. Others geopolitical zones specifically South South, North East and North West revealed that males have higher percentage of intestinal parasites than women. The South East only presented the female gender as leading carriers. This table has made it clear that sex distribution is not a confounding factor in intestinal infection as both sexes are equally susceptible eventhough the work done by Amuta [29] in the North West revealed that pre-menstrual women were infected with Entamoeba histolytica (18.9\%) and Entamoeba coli (21.6\%).

Four zones; South West, North Central, North East and North West all have children aged 5-19 years as worst infected. Egwunyenga and Kirwan both reported high incidence rate of Ascaris lumbricoides in children [29] - [31]. This raises another call for re-assessment of health education as an effective form of intervention for positive behavior change as recommended by Adanyi [31].

\section{CONTROL AND CURRENT EFFORT AT ERADICATION}

The Water, Sanitation and Hygiene (WASH) intervention programme has been effective in reducing incidences of helminth infections in the country. However, strong resistance to the programme has largely been attributed to peoples' attitudes and behaviours to sanitation and hygiene. It is therefore necessary that the programme be geared towards working on peoples' attitudes and behaviours through health education and public enlightenment. WASH interventions include environmental cleanliness, healthy living, poverty reduction and gender equity [33]. These benefits act as barriers to transmission of diseases from the environment to the human body [34]. WHO estimated that more than $9 \%$ of the disease burden and $6 \%$ of deaths could be prevented by improving the WASH intervention programme.

Drug treatment for those already infected is administered in a similar way as the National Immunization Program to alleviate the suffering of the infected population and prevent the parasites they harbor from passing into the environment and infecting others. Sanitary improvements such as safe, efficient and hygienic management of water (from extraction, through transport and storage, to use, particularly for drinking); safe, efficient and hygienic disposal of feces is encouraged with a regular and effective use of water (with a scouring agent like ash or soap) for hand washing after contact with stool. Regular, intermittent de-worming with Albendazole even in the absence of symptoms like constitutional abdominal ache, vomiting and diarrhea. Hygienic food preparation and health education is also advocated to encourage individuals to adopt positive behavioral change.

Partnership for Child Development recently supported the federal government via a deworming exercise in Osun state targeting 7,500 school children. This effort is in consolidation of the government-led mapping carried out across six states in Nigeria. This will be used to construct an effective treatment plan which ensures that school children are dewormed and treated for infections posing a threat to their 
health, nutrition and development.

\section{CONCLUSION AND RECOMMENDATIONS}

Parasitic helminthiasis is more frequent in poor populations and in immune-compromised individuals, preventive measures and surveillance systems must be emphasized. Potable water should also be provided to the rural dwellers through sinking of boreholes in their communities. Periodic assessment of the intervention programme is also important.

Health education on exhibiting good sanitary habit and personal hygiene should be carried out regularly in communities and the need for regular deworming should be emphasized as paramount factor in combating the menace of the infestation. Government should also endeavor to provide basic amenities like provision of safe, portable drinking water. This study shows high levels of intestinal parasites amongst children. Therefore, it is recommended that consistent follow up from health and environmental officers in monitoring of residential areas, hygiene practices, quality of raw food items sold in the open, curbing of open defecation and other crucial health maintenance habits is required for there to be significant improvement in terms of reduced prevalence or even complete elimination intestinal parasitic infestattions.

Preventive chemotherapy is also recommended. This is defined as the widespread delivery of safe, single-dose, quality-assured medicine either alone or in combination at regular intervals to treat selected diseases. It aims to reduce the burden of disease and is recommended by WHO as a public health intervention for helminthiases [35].

WHO promotes the use of five public health strategies to control, eliminate and eradicate NTDs; these provide preventive chemotherapy, innovative and intensified diseasemanagement, vector control and pesticide management, safe drinking-water, basic sanitation and hygiene services and education and veterinary public-health services using the onehealth concept [35]. These should be adopted in their entirety for effective control and elimination of intestinal parasites in Nigeria.

\section{REFERENCES}

[1] Dr. Rashidul Haque. Human Intestinal Parasites: J Health Popul Nutr. 2007 Dec; 25(4):387-391.

[2] Savioli L, Albonico M. Soil-transmitted helminthiasis: Nat Rev Microbiol 2004; 2:618-9.

[3] Cappello M. Global health impact of soil-transmitted nematodes: Pediatr Infect Dis J 2004; 23:663-4

[4] Brig Hemant Kumar (Retd), Capt Kalpana Jain (Retd), Maj Rahul Jain. A study of prevalence of intestinal worm infestation and efficacy of anthelminthic drugs: Medical journal armed forces India; 70 (2014) $144 \mathrm{e} 148$.

[5] WHO. Soil-transmitted Helminth Infections: Fact sheetN_366 at: www.who.int/media centre/factsheets/fs366/en/.

[6] WHO. Technical Report Series-972. Research Priorities for Helminth Infections: Technical Report of the TDR Disease Reference Group on Helminth Infections World Health Organisation; (2012).

[7] Stephenson LS, Latham MC, Ottesen EA. Malnutrition and parasitic helminth infections: Parasitology 2000; 121:S23-38.

[8] Stoltzfus RJ, Chway HM, Montresor A, Tielsch JM, Jape JK, Albonico $\mathrm{M}$ et al. Low dose daily supplementation improves iron status and appetite but not anemia, whereas quarterly anthelminthic treatment improves growth, appetite and anemia in Zanzibari preschool children: J Nutr 2004; 134:348-56.
[9] Drake LJ, Jukes MCH, Sternberg RJ, Bunday DAP. Geohelminth infections (ascariasis, trichiuriasis, and hookworm): cognitive and development impacts. Sem Paediatr Infect Dis 2000; 11:245-51.

[10] Guyatt HL. Do intestinal nematode affect productivity in adulthood: Parasitol Today 2000; 16:153-8.

[11] Davis AN, Haque R, Petri WA, Jr. Update on protozoan parasites of the intestine: Curr Opin Gastroentrol 2002; 18:10-4.

[12] World Health Organization. Amoebiasis. WHO Weekly Epdemiol Rec 1997; 72:97-100.

[13] Petri WA, Jr., Haque R, Lyerly D, Vines RR. Estimating the impact of amebiasis on health: Parasitol Today 2000; 16:320-21.

[14] Herwaldt BL. Cyclospora cayetanensis: review, focusing on the outbreaks of cyclosporiasis in the 1990s. Clin Infect Dis 2000; 31:1040-57.

[15] Okhuysen PC, White AC, Jr. Parasitic infections of the intestine: Curr Opin Infect Dis 1999;12:467-72.

[16] Nwosu ABC. The community of soil transmitted helminth infection of humans in a hyper-endemic area of Southern Nigeria: Annal. Trop. Med. Parasit., 1981; 75: 197-203.

[17] Udonsi JK. Necator americanus: a cross-sectional study of rural community in relayoion to some clinical signs: Annal. Trop. Med. Parasitol 1984; 78: 443-445.

[18] Albonico M, Ramsan M, Wright V, Jape K, Haji HJ, Taylor M, Savioli $\mathrm{L}$ and Bickle $\mathrm{O}$. Soil transmitted nematode infections and mebendazole treatment in Mafia Island School children: Annal. Trop. Med. Parasitol 2002; 96: 717-726.

[19] Sackey ME, Weigel MM, Armijos RX. Predictors and nutritional consequences of intestinal parasitic infections in rural Ecuadorian children: J. Trop. Pediatr., 2003; 49: 17-23.

[20] Edungbola LD and Obi AA. A review of human intestinal parasites in Nigeria; challenges and prospects for integrated control: Nig. J. Parasitol 1992; 13: 27-37.

[21] Nwoke BEB. The impact of changing human environment and climate change on emerging and re-emerging parasitic diseases: 28th Annual Conference of Nigerian Society for Parasitology. Owerri, Nigeria. 2004; pp. 1-37.

[22] Amuta EU, Houmsou RS. Assessment of nutritional status of school children in Makurdi, Benue State: Asian Network for Scientific information: Pak. J. Nutr., 2009; 8: 691-694.

[23] Anosike, J.C.; Nwoke, B.E.B; Obiukwu, C.E; Nkem, B.I; Nwoke, E.A. Epidemiological implications of Cockroaches and houseflies in the desimination of diseases in the tropical rainforest zone of south eastern Nigeria (In press): 2004 Ann. Agric. Environ. Med.

[24] Arosoye A S., Hassan A A. and Oyebamiji D A. Survey of Human Intestinal Parasites in Communities within Ibadan, Southwestern, Nigeria: Acta Scientific Microbiology 1.7 2018; 61- 67.

[25] Damen J G, Luka J, Biwan E I, Lugos M. Prevalence of intestinal parasites among pupils in rural North Eastern, Nigeria: Niger Med $\mathbf{J}$ 2011; 52:4-6.

[26] Gimba, U.N.; Dawam, N.N. Epidemiological status of intestinal parasitic infection rates in children attending Gwagwalada Township Clinic, FCT-Abuja, Nigeria: American Journal of Research Communication, 2015; 3(2): 97-110\} www.usa-journals.com, ISSN: 2325-4076.

[27] Kpurkpur Tyoalumun, MSc; Sani Abubakar, MSc; Nongu Christopher, MLT. Prevalence of Intestinal Parasitic Infections and their Association with Nutritional Status of Rural and Urban Pre-School Children in Benue State, Nigeria: International Journal of $\mathrm{MCH}$ and AIDS 2016; Volume 5, Issue 2, 146-152.

[28] Amuta EU.; Houmsou RS.; Mker SD. Knowledge and risk factors of intestinal parasitic infections among women in Makurdi, Benue state: Asian Pacific Journal of Tropical Medicine 2010; 993-996.

[29] Egwunyenga OA, Ajayi JA, Duhlinska-Popova DD. Transplacental passage of Plasmodium falciparum and seroevaluation of newborns in Northern Nigeria: SE Asia J Trop Med Pub Hlth 1997; 28: 741-745.

[30] P. Kirwan, S.O. Asaolu, T.C. Abiona, A.L. Jackson, H.V. Smith and C.V. Holland. Soil-transmitted helminth infections in Nigerian children aged 0-25 months: Journal of Helminthology 2009; 00, 1-6.

[31] Adanyi C. S., Audu P. A, Luka S. A. and Adanyi D. N. The impact of health education on the prevalence of helminthosis in primary school children in Zaria, Kaduna State: 2014; Arch. Appl. Sci. Res., (2011), 3 (3):6-11.

[32] Waddington, H., Snilstveit, B., White, H., Fewtrell, L. Water, sanitation and hygiene interventions to combat childhood diarrhoea in developing countries: International Initiative for Impact Evaluation. 2009; Synthetic Review 001.

[33] Kosek, M., Bern, C. and Guerrant, R.L. The global burden of diarrhoeal disease, as estimated from studies published between 1992 and 2000: Bulletin of the World Health Organization 81, 2003; 197-204. 
[34] Sustaining the drive to overcome the global impact of neglected tropical diseases: second WHO report on neglected diseases (2013).

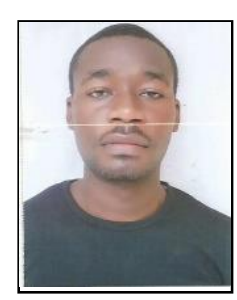

First Author's name is Mr Funso-Aina Oluwatobiloba Ibukunoluwa was born on the 5th of September, 1991 in Somolu LGA of Lagos state and hails from Iye-Ekiti, Ekiti state, Nigeria.

His robust training cuts across academic, spiritual, voluntary and public service spheres right from his undergraduate schooling.

He enjoys goal driven tasks and values integrity, humility and timeliness. The author is an aspiring public health practitioner and loves research in medical science. His academic career began in 2009 at Ladoke Akintola University of Technology, Ogbomoso, Oyo state, Nigeria where he obtained a B.Tech in Science Laboratory Technology (Biology/Microbiology) and graduated in 2015. He's a qualified Project Management Professional having undergone adequate training and executed projects.

His voluntary service spans over seven (7) years in diverse nongovernmental organizations. During his youth service at Ihievbe community, Owan East LGA of Edo state in 2016, he served as axes coordinator and community development service (CDS) president. Landmark projects were executed namely; branded free exercise books and free skills acquisition for the students with sensitization on social ills and free medical tests and treatment for the communities' residents. He doubled as the secretary of Nigeria Christian Corpers' Fellowship, Afuze zone. This service was also maximized to actualize community service responsibilities at no cost on attendees.

He currently resides in Asaba, Delta state, Nigeria and an employee of Drugfield Pharmaceuticals Limited. He's undertaking a higher degree in public health at Nnamdi Azikiwe University. Also a stakeholder and on the advisory team of an ongoing project in Northern Nigeria named Project EAT (Empower an Almajiri Today) and a project manager coordinating secondary school rallies for Wake-Up Call Africa Initiative. Both organizations are nongovernmental.

Above all, he is a lover of God and ensures he represents His interest on all fronts. A notable self-development training he attended is the first edition of Workplace readiness training for young graduates by Covenant Capital in Lagos state, Nigeria in 2015. 